\title{
PENGARUH SISTEM INFORMASI SUMBER DAYA MANUSIA DAN DISIPLIN KERJA TERHADAP KINERJA PADA KARYAWAN CV. CIHANJUANG INTI TEKNIK CIMAHI
}

\author{
Wala Erpurini \\ Fakultas Ekonomi Universitas Nasional Pasim \\ Jalan Dakota No 8a Sukaraja Bandung \\ wala_erpurini@yahoo.com
}

\begin{abstract}
ABSTRAK
Tujuan dari penelitian ini adalah untuk mengetahui pengaruh sistem informasi SDM dan disiplin kerja terhadap kinerja pada karyawan CV. Cihanjuang Inti Tekhnik. Populasi dalam penelitian ini adalah seluruh karyawan. Sementara sampel yang diambil adalah sebanyak 60 responden (semua karyawan) dengan menggunakan teknik penarikan sampling jenuh. Teknik analisa data yang digunakan adalah analisis jalur. Hasil penelitian melalui analisis deskriptif menunjukkan bahwa sistem informasi SDM, disiplin kerja, dan kinerja berada pada kategori cukup baik. Kemudian pengujian hipotesis menunjukkan bahwa variabel sistem informasi SDM dan disiplin kerja berpengaruh terhadap kinerja. Hasil perhitungan korelasi, besarnya pengaruh sistem informasi SDM terhadap kinerja adalah 40,2\%, dan pengaruh disiplin kerja terhadap kinerja adalah 24,2\%, sementara pengaruh sistem informasi SDM dan disiplin kerja terhadap kinerja sebesar 64,6\% sedangkan sisanya dipengaruhi oleh variabel lain yang tidak diteliti.
\end{abstract}

Kata kunci: Sistem Informasi SDM, Disiplin Kerja , Kinerja.

\section{PENDAHULUAN}

Setiap perusahaan harus
mempunyai suatu sistem untuk
mengumpulkan dan memelihara data
yang menjelaskan sumber daya
manusia, mengubah data menjadi
informasi dan menyampaikan informasi
tersebut kepada pemakai.

Manajemen sistem informasi berarti suatu sistem informasi yang bersifat integratif. Sistem informasi yang integratif adalah suatu sistem dimana semua unit organisasi memiliki suatu kerangka informasi tunggal untuk pengumpulan dan penggunaan informasi yang diperlukan. Aktifitas organisasi memerlukan berbagai sumber daya, salah satu diantaranya yaitu sumber daya manusia. Sumber daya manusia memegang peranan penting sekaligus pemegang kunci keberhasilan organisasi dalam mencapai tujuan organisasi yang direncanakan, sehingga maju mundurnya suatu organisasi akan sangat tergantung sampai seberapa jauh kualitas sumber daya manusia yang ada dalam organisasi tersebut. 
- Perusahaan memiliki peran penting terhadap perkembangan tenaga kerja. Hal ini dapat dilakukan dengan cara memperhatikan setiap Sumber Daya Manusia yang diolah untuk melakukan tanggung jawabnya atau proses pencapaian tujuan perusahaan. Sistem informasi sumber daya manusia (SISDM), merupakan salah satu faktor yang memegang peranan penting untuk sumber daya manusia yang berkualitas.

Kinerja pegawai merupakan hasil pencapaian dari seorang pekerja dalam menyelesaikan tugas dan peran yang dilakukan dalam suatu organisasi.

Sumber daya manusia atau karyawan yang bekerja di CV. Cihanjuang Inti Teknik (CINTEK), merupakan karyawan yang diambil dari lingkungan lokasi CV. Cihanjuang Inti Teknik (CINTEK) sendiri. Hal ini didasarkan karena perusahaan ini dibentuk untuk membantu mensejahterakan masyarakat sekitar khususnya yang berlokasi di daerah Cihanjuang Kota Cimahi. Menurut hasil survey dari wawancara bersama pihak Humas dan SDM CV. Cihanjuang Inti Teknik (CINTEK) kinerja karyawan sangat dipengaruhi oleh latar belakang pendidikan, lingkungan, dann sistem yang diterapkan pada UKM ini.

Berdasarkan pada fenomena tersebut maka penulis tertarik mengkaji lebih lanjut tentang sistem informasi sumber daya manusia dan disiplin kerja terhadap kinerja karyawan di $\mathrm{CV}$. Cihanjuang Inti Teknik Cimahi, dengan judul :

"PENGARUH

SISTEM

INFORMASI SUMBER DAYA MANUSIA DAN DISIPLIN KERJA TERHADAP KINERJA PADA KARYAWAN CV. CIHANJUANG INTI TEKNIK CIMAHI".

Peneliti mengajukan hipotesis penelitian sebagai berikut :

H1 : Sistem Informasi Sumber Daya Manusia berpengaruh positif dan signifikan terhadap Kinerja Karyawan di CV. Cihanjuang Inti Teknik Cimahi

H2 : Disiplin Kerja berpengaruh positif dan signifikan terhadap Kinerja Karyawan di CV. Cihanjuang Inti Teknik Cimahi

H3 : Sistem Informasi Sumber Daya Manusia dan Disiplin Kerja berpengaruh Positif dan signifikan terhadap Kinerja Karyawan di CV. Cihanjuang Inti Teknik Cimahi 


\section{KAJIAN PUSTAKA}

Menurut Malayu S.P Hasibuan (2014 : 10) Manajemen Sumber Daya Manusia adalah ilmu dan seni mengatur hubungan dan peranan tenaga kerja agar efektif dan efisien membantu terwujudnya tujuan perusahaan, karyawan, dan masyarakat.

Sistem Informasi Sumber daya Manusia menurut Veithzal Rivai ( 2014 : 729 ) yaitu prosedur sistematik untuk pengumpulan, menyimpan, mempertahankan, menarik dan memvalidasi data yang dibutuhkan oleh sebuah perusahaan untuk meningkatkan keputusan SDM. Pengertian Disiplin kerja Malayu S.P Hasibuan ( 2014 : 193 ) menyatakan bahwa Disiplin kerja kesadaran dan kesediaan seseorang menaati semua peraturan perusahaan dan norma-norma sosial yang berlaku.

Kinerja oleh Anwar Prabu Mangkunegara ( 2011 : 67 ) menyatakan (prestasi kerja) adalah hasil kerja secara kualitas dan kuantitas yang dicapai oleh seorang pegawai dalam melaksanakan tugasnya sesuai dengan tanggung jawab yang diberikan kepadanya.

\section{METODE PENELITIAN}

Penelitian ini menggunakan metode deskriptif dan asosiatif. Metode deskriptif adalah suatu penelitian untuk mengetahui nilai variabel mandiri baik satu variabel atau lebih tanpa membuat suatu perbandingan atau dihubungkan dengan variabel lainnya, sedangkan metode asosiatif adalah digunakan untuk melihat hubungan antara dua atau lebih variabel. (Bambang S. Soedibjo 2013:7)

Dalam penelitian ini metode deskriptif juga digunakan untuk melihat gambaran mengenai masing-masing variabel mandiri seperti yang ditunjukkan untuk melihat hubungan kedua variabel tersebut.

Agar konsep variabel yang diukur dalam penelitian dapat diukur maka perlu dilakukan pendefinisian terhadap variabel tersebut agar terdapat kesamaan persepsi dalam mengkaji konsep yang sedang diteliti. Definisi ini merupakan definisi konkrit atau karakteristik konsep/konstruk yang akan diukur (Bambang S Soedibjo, 2013:59).

Dari konsep yang diajukan dalam penelitian ini terdiri dari dua variabel, yaitu variabel bebas (independent) dan variabel terikat (dependent). Variabel bebas adalah sistem informasi sumber daya manusia 
$\left(\mathrm{X}_{1}\right)$, disiplin kerja $\left(\mathrm{X}_{2}\right)$ dan variabel terikat adalah kinerja (Y).

\section{HASIL PENELITIAN}

Setiap indikator pertanyaan yang digunakan untuk mengukur variabel X1 (sistem informasi sumber daya manusia) pada CV. Cihanjuang Inti Teknik ini adalah valid, karena nilai koefisien korelasi lebih besar dibanding 0,3. Pengujian validitas pada penelitian ini dilakukan dengan analisis item, dimana skor butir dikorelasikan dengan skor total. Rumus yang digunakan untuk mengkorelasikan tiap butir instrumen adalah product moment. Setiap indikator pertanyaan yang digunakan untuk mengukur variabel X2 (disiplin kerja) pada CV. Cihanjuang Inti Teknik ini adalah valid, karena nilai koefisien korelasi lebih besar dibanding 0,3.

Dapat diketahui bahwa setiap indikator pertanyaan yang digunakan untuk mengukur variabel $\mathrm{Y}$ (kinerja) pada $\mathrm{CV}$. Cihanjuang Inti Teknik ini adalah valid, karena nilai koefisien korelasi lebih besar dibanding 0,3 .

Pengujian terhadap konsistensi internal yang dimiliki oleh suatu istrumen merupakan alternatif lain yang dapat dirasakan oleh peneliti untuk menguji reliabilitas, teknik yang digunakan untuk mengukur konsistensi internal adalah teknik alpha croncbach's. Merupakan indeks yang cukup sempurna dalam mengukur reliabilitas konsistensi antar butir.

Berdasarkan output dari SPSS Versi 16 di atas, diperoleh nilai Cronbach's Alpha pada variabel sistem informasi sumber daya manusia sebesar 0,786 yaitu di atas 0,700 ini artinya, sistem informasi sumber daya manusia adalah reliabel yang berada pada kategori layak. Pengujian terhadap konsistensi internal juga dilakukan pada variabel disiplin kerja, menggunakan rumus alpha croncbach's. Karena nilai koefesien alpha croncbach's merupakan indeks yang cukup sempurna dalam mengukur reliabilitas konsistensi antar butir.

Berdasarkan output dari SPSS Versi 16 di atas, diperoleh nilai Cronbach's Alpha pada variabel lingkungan kerja sebesar 0,787 yaitu di atas 0,700 ini artinya, variabel lingkungan kerja adalah reliabel yang berada pada kategori layak. Pengujian terhadap konsistensi internal juga dilakukan pada variabel kinerja, menggunakan rumus alpha croncbach's. Karena nilai koefesien alpha croncbach's merupakan indeks yang cukup sempurna dalam mengukur reliabilitas konsistensi antar butir.

Berdasarkan output dari SPSS Versi 16 di atas, diperoleh nilai Cronbach's Alpha pada variabel kinerja karyawan sebesar 0,794 yaitu di atas 0,700 ini artinya, variabel kinerja karyawan adalah reliabilitas yang berada pada kategori layak. 


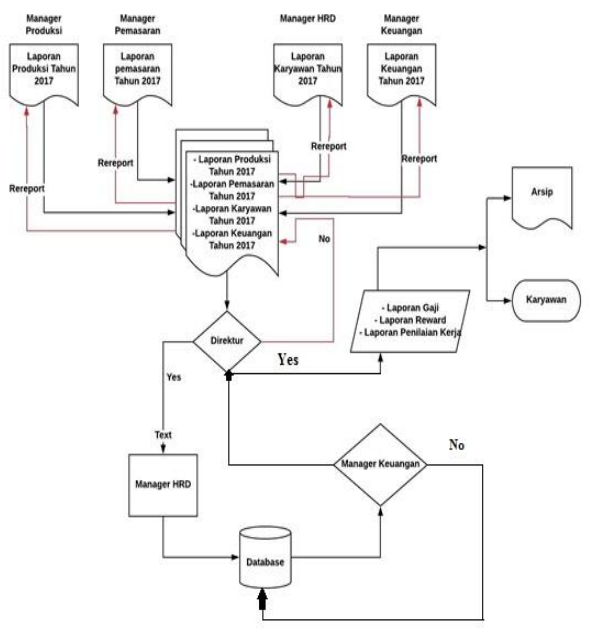

Gambar 1. Flowchart Sistem Informasi Sumber Daya Manusia

Sumber : Data sekunder CV.Cihanjuang Inti Teknik Cimahi

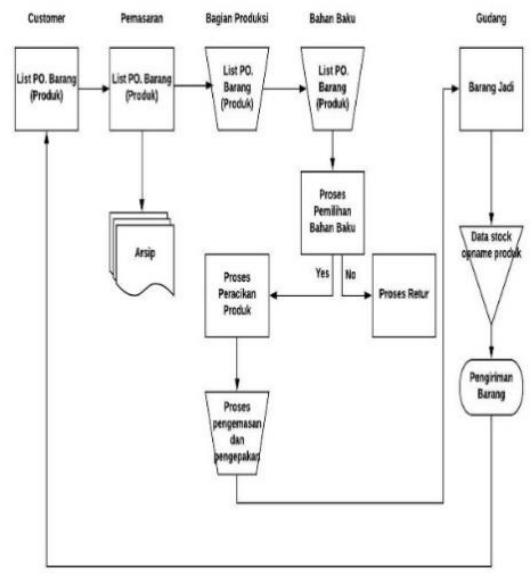

Gambar 2. Flowchart Sistem

\section{Informasi Pemasaran}

Sumber : Data sekunder CV.

Cihanjuang Inti Teknik Cimahi

Hasil analisis deskriptif pada variabel sistem informasi sumber daya manusia dilakukan dengan menggunakan nilai bobot yang didapatkan dari hasil jawaban responden berdasarkan kuisioner yang diberikan, adapun nilai bobot tersebut dapat dianalisis ada delapan pernyataan yang diukur pada variabel sistem informasi sumber daya manusia. Ratarata bobot aktual pada variabel sistem informasi sumber daya manusia diperoleh sebesar 189,125 dan dibulatkan menjadi 189 dimana nilai rata-rata tersebut masuk kedalam kategori cukup baik yang berada pada interval 156 - 203, sesuai dengan perhitungan nilai bobot standar yang telah ditetapkan sebelumnya.

Berdasarkan perhitungan dari seluruh pernyataan diketahui bahwa pernyataan indikator tertinggi terdapat pada pernyataan keenam yang mengukur sistem informasi sumber daya manusia yang menghasilkan data absensi dengan lengkap dengan bobot aktual sebesar 196. Nilai bobot ini mengartikan bahwa database dari data absensi cukup membantu kinerja karyawan pada divisi hrd, penetapan nilai ini disesuaikan dengan perhitungan nilai bobot standar.

Kemudian, berdasarkan perhitungan dari seluruh pernyataan diketahui bahwa pernyataan indikator terendah terdapat pada pernyataan kesatu yang mengukur sistem informasi 
sumber daya manusia menyediakan data karyawan secara lengkap sebesar 176. Nilai bobot ini mengartikan bahwa sistem informasi sumber daya manusia cukup baik menyediakan data karyawan penetapan nilai ini disesuaikan dengan perhitungan nilai bobot standar.

Hasil analisis deskriptif pada variabel disiplin kerja dilakukan dengan menggunakan nilai bobot yang didapatkan dari hasil jawaban responden . delapan pernyataan yang diukur pada variabel disiplin kerja. Adapun rata-rata bobot aktual pada variabel lingungan kerja diperoleh sebesar 173,75 atau dibulatkan menjadi 174, dimana nilai rata-rata tersebut masuk kedalam kategori cukup baik yang berada pada interval 156 - 203 sesuai dengan perhitungan nilai bobot standar yang telah ditetapkan sebelumnya.

Hasil analisis deskriptif pada variabel kinerja dilakukan dengan menggunakan nilai bobot yang didapatkan dari hasil jawaban responden berdasarkan kuisioner yang diberikan,

Ada enam pernyataan yang diukur pada variabel kinerja. Adapun rata-rata bobot aktual pada variabel kinerja karyawan diperoleh sebesar 185, dimana nilai rata-rata tersebut masuk kedalam kategori cukup baik yang berada pada interval 156 - 203 sesuai dengan perhitungan nilai bobot standar yang telah ditetapkan sebelumnya.

Untuk melihat korelasi antara sistem informasi sumber daya manusia dan lingkungan kerja secara parsial (masing-masing) dapat dilihat pada tabel sebagai berikut :

\section{Tabel 1. Nilai Korelasi}

\begin{tabular}{|c|c|c|c|}
\hline \multicolumn{4}{|c|}{ Correlations } \\
\hline & & SISDM & Disiplin \\
\hline \multirow[t]{3}{*}{$\begin{array}{l}\text { SISD } \\
\text { M }\end{array}$} & $\begin{array}{l}\text { Pearson } \\
\text { Correlation }\end{array}$ & 1 & \\
\hline & Sig. (2-tailed) & & .000 \\
\hline & $\mathrm{N}$ & 60 & 60 \\
\hline \multirow[t]{3}{*}{ Disipli } & $\begin{array}{l}\text { Pearson } \\
\text { Correlation }\end{array}$ & $.695^{* *}$ & 1 \\
\hline & Sig. (2-tailed) & .000 & \\
\hline & $\mathrm{N}$ & 60 & 60 \\
\hline \multicolumn{4}{|c|}{$\begin{array}{l}\text { **. Correlation is significant at the } 0.01 \text { level ( } 2 \text { - } \\
\text { tailed). }\end{array}$} \\
\hline \multicolumn{4}{|c|}{ Sumber : Hasil Olahan Data Primer 2018} \\
\hline
\end{tabular}
korelasi antara variabel sistem informasi sumber daya manusia dan lingkungan kerja sebesar 0,695 yang berarti berpengaruh secara positif terhadap kinerja.

Untuk mengetahui seberapa besar pengaruh sistem informasi sumber daya manusia terhadap kinerja pada karyawan CV. Cihanjuang Inti Teknik Cimahi, maka dilakukan perhitungan statistik dengan menggunakan model analisis jalur (Path Analysis) melalui 
bantuan program SPSS versi 16, dengan hasil sebagai berikut :

Tabel 2. Model Analisis Jalur

Coefficients $^{\mathrm{a}}$

\begin{tabular}{|c|c|c|c|c|c|}
\hline \multirow[b]{2}{*}{ Model } & \multicolumn{2}{|c|}{$\begin{array}{l}\text { Unstandardize } \\
\text { d Coefficients }\end{array}$} & $\begin{array}{c}\text { Standard } \\
\text { ized } \\
\text { Coeffici } \\
\text { ents }\end{array}$ & & \\
\hline & B & $\begin{array}{l}\text { Std. } \\
\text { Error }\end{array}$ & Beta & $\mathrm{t}$ & Sig. \\
\hline 1 (Constant) & 1.425 & 1.747 & & .816 & .418 \\
\hline SISDM & .394 & .082 & .527 & 4.80 & .000 \\
\hline Disiplin & .308 & .099 & .342 & $\begin{array}{r}3.11 \\
7\end{array}$ & .003 \\
\hline
\end{tabular}

a. Dependent Variable: Kinerja

Sumber : Hasil Olahan Data Primer 2018

Hasil Perhitungan Perhitungan Analisis

Jalur

1. Pengaruh langsung $\mathrm{X} 1$ terhadap $\mathrm{Y}$

$$
\begin{aligned}
& =(\text { pyx } 1) \cdot(\text { pyx } 1) \\
& =0,527 \times 0,527 \\
& =\mathbf{0 , 2 7 7 7 2 9}
\end{aligned}
$$

Pengaruh tidak langsung X1

terhadap Y

$$
\begin{aligned}
& =(p y x 1) \cdot(r x 1 \times 2) \cdot(p y x 2) \\
& =0,527 \times 0,695 \times 0,342 \\
& =\mathbf{0 , 1 2 5 2 6 2 6 3}
\end{aligned}
$$

\section{Total pengaruh $\mathrm{X} 1$ terhadap $\mathrm{Y}=$}

$$
\begin{aligned}
&(p y x 1) \cdot(\text { pyx1)+ } \\
&(p y x 1) \cdot(r \times 1 \times 2) \cdot(p y x 2) \\
&=0,277729+ \\
& 0,12526263 \\
&=\mathbf{0 , 4 0 2 9 9 1 6 3 = 4 0 , 2 \%}
\end{aligned}
$$

Untuk mengetahui seberapa besar pengaruh disiplin kerja terhadap kinerja pada karyawan CV. Cihanjuang Inti Teknik Cimahi, maka dilakukan perhitungan statistik dengan menggunakan rumus dari model analisis jalur (Path Analysis) melalui bantuan program SPSS versi 16, dengan hasil sebagai berikut :

Pengaruh langsung X2 terhadap Y

$$
\begin{aligned}
& =(\text { pyx } 2) \cdot(\text { pyx } 2) \\
& =0,342 \times 0,342 \\
& =\mathbf{0 , 1 1 6 9 6 4}
\end{aligned}
$$

Pengaruh tidak langsung x2 terhadap

$$
\begin{aligned}
\mathrm{y} & =(p y x 2) \cdot(r \times 1 \times 2) \cdot(p y x 1) \\
& =0,342 \times 0,695 \times 0,527 \\
& =\mathbf{0 , 1 2 5 2 6 2 6 3}
\end{aligned}
$$

\section{Total pengaruh $\mathrm{X} 2$ terhadap $\mathrm{Y}=$}

$($ pyx2). (pyx2)+

(pyx2). (rx1x2). (pyx1)

$=0,116964+0,12526263$

$=0,24222663=24,2 \%$

Besarnya pengaruh sistem informasi sumber daya manusia (X1) dan disiplin kerja (X2) terhadap kinerja (Y) secara bersama-sama (simultan) dapat diketahui dengan cara menghitung koefisien determinasi (KD) setelah mengetahui nilai R2. Nilai R2 dapat dilihat dari tabel 4.14, nilai $\mathrm{R}$ square yaitu nilai yang digunakan untuk 
melihat seberapa besar pengaruh variabel lain, sebesar 0,646

Hasil ini, mengartikan bahwa pengaruh sistem informasi sumber daya manusia (X1) dan disiplin kerja (X2) terhadap kinerja (Y) secara simultan (bersama-sama) sebesar 64,6\%.

Adapun dilihat dari jumlah perhitungan yang penulis hitung antara total pengaruh $(\mathrm{X} 1)$ dan total pengaruh (X2) adalah sebagai berikut:

Total pengaruh (pengaruh bersama)

$=$ total pengaruh $\mathrm{X} 1+$ total pengaruh $\mathrm{X} 2$

$=0,40299163+0,24222663$

$=0,64521826$

Nilai R2 didapat sebesar 0,646 artinya sebesar $64,6 \%$ variasi variabel dependen (Y) dipengaruhi variabel independen. Sementara sisanya 35,4 $\%(1-0,634)$ dipengaruhi hal lain diluar variabel yang diteliti pada penelitian ini seperti kompetensi, lingkungan kerja, gaya kepemimpinan, budaya organisasi dan variabel lainnya. Sedangkan nilai koefisien eror atau koefisien residual dihitung sebagai berikut

$$
\begin{aligned}
P_{y \varepsilon} & =\sqrt{1-R_{Y X 1 X 2}^{2}} \\
P_{y \varepsilon} & =\sqrt{1-0,646} \\
P_{y \varepsilon} & =\sqrt{0,354} \\
& =\mathbf{0 , 5 9 4 9 7 8 9 9 1}
\end{aligned}
$$

Berdasarkan perhitungan maka dapat didapat nilai persamaan struktural sebagai berikut :

$$
\begin{aligned}
& \mathrm{Y}=0,527 \mathrm{X} 1+0,342 \mathrm{X} 2+ \\
& 0,594978991 \mathrm{u}
\end{aligned}
$$

1. Cimahi termasuk pada kategori cukup baik. Hal ini didasarkan pada hasil distribusi frekuensi dan pembobotan yang telah dihitung dari jawaban responden dan diperoleh nilai rata-rata sebesar 173,75 , dimana skor rata-rata tersebut masuk kedalam kriteria bobot dalam interval 156 - 203 yaitu kategori cukup baik.

2. Kinerja pada CV Cihanjuang Inti Tekhnik Cimahi termasuk pada kategori cukup baik. Hal ini didasarkan pada hasil distribusi frekuensi dan pembobotan yang telah dihitung dari jawaban responden dan diperoleh nilai rata-rata sebesar 185 , dimana skor rata-rata tersebut masuk kedalam kriteria bobot dalam interval 156 - 203 yaitu kategori cukup baik.

3. Besarnya pengaruh sistem informasi sumber daya manusia (X1) terhadap Kinerja (Y) data dihitung melalui pengaruh langsung yang mendapatkan hasil sebesar 0,277729 dan jika dihitung pengaruh secara tidak langsung mendapatkan hasil sebesar 0,12526263, sehingga total 
pengaruh antara sistem informasi sumber daya manusia (X1) terhadap kinerja (Y) adalah 0,40299163 atau 40,2\%. Yang mengartikan bahwa variabel sistem informasi sumber daya manusia (X1) berengaruh secara signifikan terhadap kinerja (Y). Jadi dapat dinyatakan bahwa hipotesis (H1) dapat diterima.

4. Adapun bahwa pengaruh disiplin kerja (X2) terhada kinerja (Y) dapat dihitung melalui pengaruh langsung yang mendapatkan hasil sebesar 0,116964 dan jika dihitung pengaruh secara tidak langsung mendapatkan hasil sebesar 0,12526263, sehingga total pengaruh antara disiplin kerja (X2) terhadap kinerja (Y) adalah sebesar 0,24222663 atau $24,2 \%$. Yang mengartikan bahwa variabel disiplin kerja (X2) berpengaruh secara signifikan terhadap kinerja (Y). Jadi dapat dinyatakan hipotesis (H2) dapat diterima.

5. Adanya pengaruh sistem informasi sumber daya manusia (X1) dan dsiplin kerja (X2) secara bersamasama terhadap kinerja (Y) diketahui dengan menghitung koefisien determinasi yaitu sebesar 0,646 dapat diperoleh melalui hasil perhitungan regresi dalam software SPSS versi 16 dan juga hasil perhitungan tersebut dapat diperoleh dari penjumlahan antara total pengaruh antara variabel sistem informasi sumber daya manusia terhadap kinerja dan variabel disiplin kerja terhadap kinerja.

\section{PENUTUP}

1. Cimahi termasuk pada kategori cukup baik dengan nilai rata-rata sebesar 173,75, dimana skor rata-rata tersebut masuk kedalam kriteria bobot dalam interval $156-203$ yaitu kategori cukup baik.

2. Kinerja pada CV Cihanjuang Inti Tekhnik Cimahi termasuk pada kategori cukup baik dengan kriteria bobot dalam interval 156 - 203 yaitu kategori cukup baik.

3. Adanya pengaruh sistem informasi sumber daya manusia (X1) terhadap Kinerja (Y) data dihitung melalui pengaruh langsung yang mendapatkan hasil sebesar 0,277729

4. Adapun bahwa pengaruh disiplin kerja (X2) terhada kinerja (Y) dapat dihitung melalui pengaruh langsung yang mendapatkan hasil sebesar 0,116964

5. Adanya pengaruh sistem informasi sumber daya manusia (X1) dan dsiplin kerja (X2) secara bersama- 
sama terhadap kinerja (Y) diketahui dengan menghitung koefisien determinasi yaitu sebesar 0,646.

\section{DAFTAR PUSTAKA}

Bambang S.Soedibjo. 2013. Pengantar Metodologi Penelitian. Bandung: STIE-STMIK Pasim.

Handoko, T. Hani. 2008. Manajemen Personalia dan Sumber Daya Manusia. Yogyakarta: Liberty

Hasibuan, Malayu. S.P. 2012. Manajemen Sumber Daya Manusia. Jakarta: PT Bumi Aksara

Hasibuan, Malayu. $\quad$ S.P. 2014. Manajemen Sumber Daya Manusia (EdisiRevisi). Jakarta: PT Bumi Aksara

Rivai, Veithzal. 2014. Manajemen Sumber Daya Manusia untuk Perusahaan : dari Teori Ke Praktik, Edisi Ketiga. Jakarta: PT. Raja Grafindo Persada.
Sunyoto, Danang. 2014. Sistem Informasi Manajemen. Yogyakarta : CAPS.

A.A. Anwar Prabu Mangkunegara. 2011. Manajemen Sumber Daya Manusia Perusahaan. Bandung: Rosda.

Sutrisno, Edy. 2017. Manajemen Sumber Daya Manusia, Cetakan KeSembilan. Jakarta: Kencana.

Suwanto. 2011. Manajemen Sumber Daya Manusia dalam Organisasi Publik dan bisnis. Bandung: Alfabeta.

Jurnal Ekonomi, Bisnis \& Entrepreneurship Volume 10 No. 1 April 2016. Pengaruh Sistem Informasi Sumber Daya Manusia Kompetensi Dan Disiplin Kerja Terhadap Kinerja Karyawan. S Mia Lamasya. STIE Pasundan Bandung. 2016. 